\title{
Reference genes selection for transcript normalization in Kenaf (Hibiscus cannabinus L.) under salinity and drought stress
}

Xiaoping Niu, Jianmin Qi, Meixia Chen, Gaoyang Zhang, Aifen Tao, Pingping Fang, Jiantang Xu, Sandra A Onyedinma, Jianguang $\mathrm{Su}$

Kenaf (Hibiscus cannabinus) is an economic and ecological fiber crop but suffers severe losses in fiber yield and quality under the stressful conditions of excess salinity and drought. To explore the mechanisms by which kenaf responds to excess salinity and drought, gene expression was performed at the transcriptomic level using RNA-seq. Thus, it is crucial to have a suitable set of reference genes to normalize target gene expression in kenaf under different conditions using real-time quantitative reverse transcription-PCR (qRT-PCR). In this study, we selected 10 candidate reference genes from the kenaf transcriptome and assessed their expression stabilities by qRT-PCR in $14 \mathrm{NaCl}$ - and PEGtreated samples using geNorm, NormFinder, and BestKeeper. The results indicated that TUB $\alpha$ and 18S rRNA were the optimum reference genes under conditions of excess salinity and drought in kenaf. Moreover, TUB $\alpha$ and 18S rRNA were used singly or in combination as reference genes to validate the expression levels of WRKY28 and WRKY32 in $\mathrm{NaCl}$ and PEG-treated samples by qRT-PCR. The results further proved the reliability of the two selected reference genes. This work will benefit future studies on gene expression and lead to a better understanding of responses to excess salinity and drought in kenaf. 
1 Reference gene selection for transcript normalization in kenaf (Hibiscus cannabinus L.) 2 under salinity and drought stress

3 Xiaoping $\mathrm{Niu}^{1}$, Jianmin Qi ${ }^{1 *}$, Meixia Chen ${ }^{1,2}$, Gaoyang Zhang ${ }^{1,3}$, Aifen Tao ${ }^{1}$, Pingping Fang ${ }^{1}$, 4 Jiantang $\mathrm{Xu}^{1}$, Sandra Onyedinma ${ }^{1}$, Jianguang $\mathrm{Su}^{4 *}$

$5{ }^{1}$ Key Laboratory for Genetics, Breeding and Multiple Utilization of Crops, Fujian Agriculture 6 and Forestry University, Fuzhou 350002, China

$7 \quad 2$ College of Life Sciences, Ningde Normal University, Ningde 350002, China

$8{ }^{3}$ College of Life Sciences, Shangrao Normal University, Shangrao 334001, China

$9{ }^{4}$ Institute of Bast Fiber Crops, Chinese Academy of Agricultural Sciences, Changsha 410205, 10 China

$11{ }^{*}$ Corresponding authors. E-mail: Qijm863@163.com; jgsu@vip.163.com

\section{Abstract}

Kenaf (Hibiscus cannabinus) is an economic and ecological fiber crop but suffers severe losses in fiber yield and quality under the stressful conditions of excess salinity and drought. To explore the mechanisms by which kenaf responds to excess salinity and drought, gene expression was performed at the transcriptomic level using RNA-seq. Thus, it is crucial to have a suitable set of reference genes to normalize target gene expression in kenaf under different conditions using real-time quantitative reverse transcription-PCR (qRT-PCR). In this study, we selected 10 candidate reference genes from the kenaf transcriptome and assessed their expression stabilities by qRT-PCR in 14 NaCl- and PEG-treated samples using geNorm, NormFinder, and BestKeeper. The results indicated that $T U B \alpha$ and $18 \mathrm{~S} r R N A$ were the optimum reference genes under conditions of excess salinity and drought in kenaf. Moreover, TUB $\alpha$ and $18 \mathrm{~S} r R N A$ were used singly or in combination as reference genes to validate the expression levels of WRKY28 and WRKY32 in NaCl- and PEG-treated samples by qRT-PCR. The results further proved the reliability of the two selected reference genes. This work will benefit future studies on gene expression and lead to a better understanding of responses to excess salinity and drought in kenaf. Keywords: reference gene; kenaf (Hibiscus cannabinus L.); salinity and drought stress; gene expression

\section{Introduction}

Agricultural productivity worldwide is adversely affected by various environmental stresses, such as water deficiency, excess salinity, extreme temperatures, chemical toxicity, and oxidative stress. These environmental factors can occur at multiple stages of plant development, resulting in reduced productivity and significant crop losses. Worse yet, drought and salinity are becoming particular widespread in many regions, affecting more than $10 \%$ of arable land and causing a global decline in the average yields of major crops by more than 50\% (Bartels \& Sunkar 2005). Therefore, understanding plant tolerance of drought and salinity is of fundamental importance and has become the focus of intensive research.

Kenaf (Hibiscus cannabinus L.) is an annual herbaceous crop of the Malvaceae family that is mostly grown in tropical regions of Asia and Africa. It has great potential applications in the pulp and paper industry, oil absorption and potting media, board making, filtration media, and 
animal feed (Ayadi et al. 2011). Kenaf has also been identified as an appealing alternative fiber source for the manufacture of a large range of paper products; pulping kenaf requires less energy and chemical inputs for processing compared with standard wood sources (Bhardwaj et al. 2005; Villar et al. 2009). What is more important is that kenaf has been recognized as a species tolerant of soil salinity and drought (Banuelos et al. 2002; Curtis \& Läuchli 1985; Francois et al. 1992). Traditional breeding approaches to improve abiotic stress tolerance have had some successes but are limited by the multigenic nature of the trait and cannot meet commercial demands due to a lack of efficient selection techniques and low levels of genetic variance and fertility (Bartels \& Sunkar 2005). Fortunately, large-scale transcriptomic analyses have recently provided a better understanding of plant stress responses, and several genes have been discovered that respond to drought, salt, or cold stress at the transcriptional level based on gene expression (Chuaqui et al. 2002; Rasmussen et al. 2013; Zhu 2002). Nevertheless, the analysis of gene expression frequently involves precise and reproducible measurements for given mRNA sequences using Northern blotting or reverse transcription-PCR (RT-PCR). Real-time quantitative RT-PCR (qRTPCR), which is a high-throughout technique with wide applications to living organisms, has become the preferred method for the validation of microarray results and the quantitation of gene expression (Chuaqui et al. 2002; Vandesompele et al. 2002). To acquire accurate information, real-time RT-PCR results are typically compared to those of an internal reference gene. As internal controls, the expression levels of these reference genes should remain constant across different tissues, experimental treatments, and developmental stages (Bustin 2002). However, many studies have found that the expression of housekeeping genes varies considerably under different experimental conditions. Thus, it was recommended that the stability of candidate reference genes must be systematically evaluated prior to their use in qRT-PCR normalization (Czechowski et al. 2005; Guenin et al. 2009; Schmidt \& Delaney 2010).

Currently, several statistical algorithms, such as geNorm (Vandesompele et al. 2002), NormFinder (Andersen et al. 2004), BestKeeper (Pfaffl, Tichopad et al. 2004), and the $\Delta \mathrm{Ct}$ method, have been developed to facilitate the identification and assessment of the best set of candidate reference genes; an increasing number of stable reference genes have been screened in many plant species, including EFl $\alpha$ and $F B X$ in Arabidopsis thaliana (Czechowski et al. 2005;

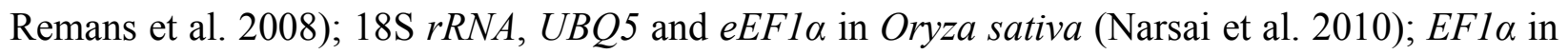
Triticum aestivum (Long et al. 2010), Glycine max (Jian et al. 2008), and Solanum tuberosum (Nicot et al. 2005); FBX and PP2A in Nicotiana benthamiana (Liu et al. 2012); PP2A, ACT4, UBQ14, FBX6, MZA, and PTB in Gossypium hirsutum (Artico et al. 2010); and EFla and $G A D P H$ in Linum usitatissimum (Huis et al. 2010). However, no systematic validation of reference genes has been performed in kenaf (H. cannabinus L.), which limits further studies of this species at the functional gene and transcriptomic levels.

In the present study, to identify reliable reference genes that could serve as normalization factors for qRT-PCR data analysis in kenaf under conditions of drought and excess salinity, 10 candidate reference genes (18S rRNA, ACT4, EF1 $\alpha, M Z A, P P 2 A, P T B, R A N, T U B \alpha, U B C$, and $U B Q$ ) were selected and studied their expression stability in a set of 14 kenaf samples exposed to drought and excess salinity using the three statistical algorithms geNorm, NormFinder, and 
BestKeeper. Furthermore, the transcription factor WRKY28, the homolog of $A$. thaliana WRKY28 (At4g18170) (Babitha et al. 2013; Chen et al. 2013), was investigated to further validate the accuracy of the novel developed reference gene(s).

\section{Materials and methods}

\section{Plant materials and treatments}

Kenaf (H. cannabinus L.) variety Fuhong 992 was used for all experiments. To achieve diseasefree materials, seeds were rinsed under running water for $10 \mathrm{~min}$ and sterilized with $5 \%$ sodium hypochlorite for $10 \mathrm{~min}$, washed three times with sterile water, and then germinated on filter paper that had been saturated with water in complete darkness at $28{ }^{\circ} \mathrm{C}$. After 3 days, seedlings were grown in the greenhouse in $25 \%$ Hoagland solution under a 16/8-h light/dark photocycle at $28 / 26^{\circ} \mathrm{C}$ (day/night). The most consistent seedlings at the 3-5 leaf stage were used for excess salinity and drought treatments or for the harvesting of different treated leaf samples. For the excess salinity treatment, seedlings were subjected to $200 \mathrm{mM} \mathrm{NaCl}$ and harvested at 2, 4, 6, 8, 12, and $24 \mathrm{~h}$. For the drought treatment, seedlings were treated with $20 \%$ (w/v) PEG6000, and samples were collected at several time points $(2,4,6,8,12$, and $24 \mathrm{~h})$. Untreated seedlings were harvested as a control at $0 \mathrm{~h}$. Three biological replicates were obtained from each group. All treated-leaf samples were employed in experiments that evaluated the stabilities of candidate reference genes under excess salinity and drought stresses.

\section{Total RNA extraction and cDNA synthesis}

All samples were snap-frozen in liquid nitrogen and stored at $-80^{\circ} \mathrm{C}$ before RNA extraction. The OMEGA isolation kit (R6827-01, USA) was used for RNA extraction, following the elimination of genomic DNA by RNase-free DNase I (TaKaRa, Japan); RNA integrity was then assessed by $2 \%$ agarose gel electrophoresis, and RNA sample quality was determined using a NanoDrop 2000 spectrophotometer (NanoDrop, Thermo Scientific). Finally, RNA samples with an A260/A280 ratio of 1.9-2.1, and an A260/A230 ratio greater than 2.0 were used for further analyses. Subsequently, first-strand cDNA was synthesized in a $20-\mu$ l reaction using the PrimeScript ${ }^{\circledR}$ RT reagent kit (TaKaRa, Japan) following the manufacturer's protocol. The quality and integrity of the cDNA were checked by NanoDrop 2000 spectrophotometry and agarose gel electrophoresis, respectively, and stored at $-20^{\circ} \mathrm{C}$ until use.

\section{Primer design, verification of PCR products, and qRT-PCR}

The sequences of 10 candidate reference genes (18S rRNA, ACT4, EF1 $\alpha, M Z A, P P 2 A, P T B$, $R A N, T U B \alpha, U B C$ and $U B Q$ ) from the transcriptomic data (unpublished data) of kenaf were subjected to a BLAST search using $A$. thaliana sequences in GenBank. The probe sequences from $A$. thaliana were used to search the transcriptome of kenaf and the kenaf expressed sequence tags database (http://www.ncbi.nlm.nih.gov/nucest/?term=kenaf). Target sequences were identified by querying homologous kenaf sequences together with $A$. thaliana complete $\mathrm{CDS}$ and probe sequences. According to these potential reference gene sequences, primers were designed using Primer 3 (http://bioinfo.ut.ee/primer3-0.4.0/primer3/) based on the following criteria: GC content $45-80 \%$, melting temperatures $58-62^{\circ} \mathrm{C}$, primer lengths $18-24 \mathrm{bp}$, and 
amplicon lengths 100-250 bp (See Table 1 for detailed primer information). To check the specificity of the amplicon, all primer pairs were initially tested via standard RT-PCR using the Premix Ex Taq ${ }^{\mathrm{TM}}$ (TaKaRa, Japan); the amplification products of each gene were verified by $2 \%$ agarose gel electrophoresis. Real-time amplification reactions were performed with the Applied Biosystems 7500 Real-Time PCR System using SYBR ${ }^{\circledR}$ Premix Ex Taq. Reactions were prepared in a $20-\mu 1$ volume containing $2 \mu \mathrm{l}$ cDNA template, $0.4 \mu \mathrm{l}$ each amplification primer, 0.4 $\mu 1$ ROX Reference Dye II, $10 \mu 12 \times$ SYBR Premix Ex Taq, and $6.8 \mu \mathrm{dH} 2 \mathrm{O}$. Amplifications were performed with an initial step of $95^{\circ} \mathrm{C}$ for $30 \mathrm{~s}$, followed by 40 cycles of denaturation at $95^{\circ} \mathrm{C}$ for $5 \mathrm{~s}$ and primer annealing at $60^{\circ} \mathrm{C}$ for $34 \mathrm{~s}$. The melting curve ranged from $60^{\circ} \mathrm{C}$ to $95^{\circ} \mathrm{C}$, and the temperature was increased in increments of $0.2^{\circ} \mathrm{C}$ per $10 \mathrm{~s}$ for all PCR products. ABI Prism Dissociation Curve Analysis Software was used to confirm the occurrence of specific amplification peaks. All reactions were carried out in triplicate with template-free negative controls being performed in parallel.

\section{Statistical analyses}

To select a suitable reference gene, geNorm, NormFinder, and BestKeeper were used to analyze the stability of each candidate reference gene. All analyses using these packages were performed according to the manufacturer's instructions. The raw $\mathrm{Ct}$ values from qRT-PCR were transformed into the required data input format. The maximum expression level (the minimum $\mathrm{Ct}$ value) of each gene was used as a control and was set to a value of 1 . Then relative expression levels were calculated from $\mathrm{Ct}$ values using the formula: $2^{-\Delta \mathrm{Ct}}$, where $\Delta \mathrm{Ct}=$ each sample $\mathrm{Ct}$ value - minimum $\mathrm{Ct}$ value. The geNorm and NormFinder algorithms further calculated the expression stability value (M) for each gene with the obtained data, whereas the BestKeeper analyses were based on untransformed $\mathrm{Ct}$ values. Standard curves were generated using Microsoft Excel 2003 by plotting cycles at threshold fluorescence $(\mathrm{Ct})$ against the logarithmic values of standard RNA amounts. Quantities of standard RNA were prepared by diluting cDNA $\left(1,10^{-1}, 10^{-2}, 10^{-3}, 10^{-4}\right.$, and $10^{-5}$; each gene in triplicate). Only $\mathrm{Ct}$ values less than 40 were used to calculate correlation coefficients ( $\mathrm{R}^{2}$ values) and amplification efficiencies (E) from the slope generated in Microsoft Excel 2003, according to the equation $\mathrm{E}=\left[10^{-(1 / \mathrm{slope})}-1\right] \times 100 \%$. All PCR assays showed efficiency values between 97\% and 118\% (Table 1). All other multiple comparisons were performed with the statistical analysis software SPSS 22.0 (SPSS Inc., USA). To validate the reference gene(s) selected in the current study, the relative expression level of WRKY28 was normalized using the $2^{-\Delta \Delta \mathrm{Ct}}$ method after collecting the mean $\mathrm{Ct}$ value of each biological replicate from the samples treated under conditions of salinity or drought for $0,4,6,8$, 12, and $24 \mathrm{~h}$. Finally, the relative increases in expression level of WRKY 28 were used to calculate the differences in the normalization of each reference gene.

\section{Results}

\section{Selection of candidate reference genes, primer specificity, and amplification efficiency}

A total of 10 candidate reference genes, including four commonly used housekeeping genes, $18 \mathrm{~S}$ $r R N A, A C T 4, T U B \alpha$, and $U B Q$, and six novel candidate reference genes, $E F 1 \alpha, M Z A, P P 2 A$, $P T B, R A N$, and $U B C$, were identified in this study (Table 1). The four novel candidates were 
validated in $A$. thaliana, $O$. sativa, or $G$. hirsutum for expression stabilities under different abiotic stresses. $R A N$ and $U B C$ have been evaluated as the optimal reference gene in Cucumis melo (Kong et al. 2014) and Platycladus orientalis (Chang et al. 2012), respectively. Additionally, the specificity of the designed primers was verified by a single band with the expected size after agarose gel electrophoresis (Fig. S1). Specificity was further confirmed by a single peak in the melting curve analysis, which was done prior to performing qRT-PCR (Fig. S2). A standard curve was generated using a 10-fold dilution of cDNA in the qRT-PCR assay to determine the amplification efficiency for each primer pair. Both $\mathrm{E}$ and $\mathrm{R}^{2}$ were calculated using the slope of the standard curve. Results indicated that the average amplification efficiency values of all primers ranged from $97.13 \%$ to $118.60 \%$ (Table 1 ).

As showed in Fig. 1 and Table 1, for all tested samples, the mean Ct values of 10 candidate reference genes had a wide range (17.89 - 34.28), and the standard deviation (SD) varied from 0.65 to 1.94 , and the coefficient of variation (CV) ranged from $2.15 \%$ to $8.64 \%$. Comparing to $\mathrm{Ct}$ values of all the candidates, $18 \mathrm{~S} r R N A$ had a highest expression level (mean $\mathrm{Ct} \pm \mathrm{SD}=17.89 \pm$ 1.55), following $A C T 4$ (mean $\mathrm{Ct} \pm \mathrm{SD}=22.17 \pm 1.24$ ) and $E F 1 \alpha$ (mean $\mathrm{Ct} \pm \mathrm{SD}=22.46 \pm 1.54$ ), whereas $M Z A$ (mean $\mathrm{Ct} \pm \mathrm{SD}=34.28 \pm 0.74$ ) accumulated less than all the others. Additionally, $P P 2 A, P T B, R A N, T U B \alpha, U B Q$ and $U B C$ showed a narrow range of mean $\mathrm{Ct}$ values, indicating that these genes were stably expressed. However, it is insufficient for evaluating gene expression stability just by the comparison of raw $\mathrm{Ct}$ values. To obtain accurate gene expression data, other approach should be combined with to validate a set of appropriate reference genes under a given conditions.

\section{Stability of reference genes analysis by geNorm}

The geNorm-based analysis was conducted to determine which reference gene(s) would be optimal in each tested sample set. As shown in Figure 2, the candidate genes were ranked accordingly to their $M$ values. Since a lower $M$ values indicates a greater stability of the reference gene, $T U B \alpha$ and $18 \mathrm{~S} r R N A$ were ranked as the most stable, with $\mathrm{M}$ values of 0.28 and 0.65 , respectively, whereas $U B C$ was the least stably expressed under conditions of drought and excess salinity (Fig. 2). The results were consistent with the pattern observed in Tables 2 and 3. When the combination of drought and salinity was considered, the same results (TUB $\alpha$ and $18 \mathrm{~S}$ $r R N A)$ were acquired for normalization $(\mathrm{M}=0.51)$ (Table 4; Fig. 2C). The geNorm algorithm can also be used to identify the optimal number of reference genes by calculating the pairwise variation (V) between normalization factors (NFn). It is proposed that an additional reference gene makes no sense to the normalization when $\mathrm{Vn} / \mathrm{n}+1$ is less than 0.15 . In this study, the data showed that a V2/3 of 0.13 was less than 0.15 , which indicated that the combination of $T U B \alpha$ and 18S $r R N A$ was sufficient for the normalization of gene expression under drought stress (Fig. 2D). For salinity stress in kenaf, a V3/4 of 0.15 was less than a V2/3 of 0.19 , which suggested that three reference genes, $T U B \alpha, 18 S \operatorname{rnNA}$, and $R A N$ were the best options for accurate normalization under salinity stress (Fig. 2D). For all drought and excess salinity samples, the same effects were observed. These results revealed that $T U B \alpha$ together with $18 \mathrm{~S} r R N A(\mathrm{~V} 2 / 3=$ 0.14 ) could provide a reliable reference for the normalization of gene expression. 


\section{Stability of reference genes analysis by NormFinder}

The NormFinder program analyzes candidate reference genes according to inter- and intragroup variations in expression. As in the geNorm method, the gene with the lowest $\mathrm{M}$ value has the most stable expression. As shown in Tables 2-4, the NormFinder analysis also identified that 18S $r R N A$ and $T U B \alpha$ were the most stably expressed genes with values of 0.12 and 0.13 under drought stress, respectively, with slight differences in the ranking order (Table 3). For the salinity samples, $P P 2 A$ and $A C T 4$ were the top two reference genes followed by $18 \mathrm{~S} r R N A$, identified by NormFinder (Table 2). For the drought and excess salinity samples, ACT4 and $18 \mathrm{~S}$ $r R N A$ were the top two genes calculated by NormFinder (Table 4). Compared with the results of geNorm and NormFinder analyses, $18 \mathrm{~S} r R N A$ was the best reference gene under salinity stress. Overall, the results obtained from NormFinder analysis were consistent with those from geNorm analysis.

\section{Stability of reference genes analysis by BestKeeper}

The BestKeeper program utilizes the unconverted $\mathrm{Ct}$ values to accomplish parametric tests on normally distributed expression levels. It evaluates the geometric mean of $\mathrm{Ct}$ values, determines the coefficient of variance (CV), and calculates a Pearson's coefficient of correlation $(r)$ of each gene. The standard deviation (SD) of the average $\mathrm{Ct}$ values are performed to generate a weighted index of most suitable normalizing genes across selected biological samples and exclude genes that are not stably expressed. The most stable genes are identified as those that exhibit the lowest $\mathrm{CV}$ and $\mathrm{SD}(\mathrm{CV} \pm \mathrm{SD})$, in relation to $r$ and $p$ values. Genes with SD greater than 1 are considered unacceptable and should be excluded. In this study, $18 \mathrm{~S} r R N A$ had $\mathrm{CV} \pm \mathrm{SD}$ values of $1.96 \pm 0.67$, showing remarkably stable expression $(r=0.911 ; p=0.004)$. TUB $\alpha$ displayed the lowest $\mathrm{CV} \pm \mathrm{SD}$ values of $1.50 \pm 0.46$, but with a lower $r$ value $(r=-0.186)$, and higher $\mathrm{p}$-value ( $p=0.692$ ), it is not possible to conclude on stable gene. UBQ, PTB, UBC, EF1 $\alpha$ and ACT4 had an $\mathrm{SD}>1.0$, thus excluding them as suitable reference genes for NaCl-treated samples (Table 2). These results are consistent with those acquired from the geNorm method. For the PEG-treated samples, $M Z A$ displayed the lowest $\mathrm{CV} \pm \mathrm{SD}=0.72 \pm 0.25$, but with $r=0.246, p=0.593$, it does not act as a suitable reference gene. $T U B \alpha(\mathrm{CV} \pm \mathrm{SD}=1.54 \pm 0.46, r=0.837$, and $p=0.019)$ and $18 \mathrm{~S} r R N A(\mathrm{CV} \pm \mathrm{SD}=4.47 \pm 0.85, r=0.940$, and $p=0.002)$ showed the potential for being normalization factors. Whereas $U B Q$ and $R A N$ had an SD value greater than 1.0, indicating that the two reference genes were not suitable for normalization (Table 3). When the two datasets from conditions of excess salinity and drought were analyzed together, although $M Z A$ and $T U B \alpha$ had a lower $\mathrm{CV} \pm \mathrm{SD}$, a lower $r$ value and higher $p$ value was observed. It is notable that $18 \mathrm{~S}$ $r R N A$ with $\mathrm{SD}>1.0$ was identified as the least stable by BestKeeper compared to the other candidate reference genes (Tables 3 and 4).

\section{Reference gene validation}

To further validate the reliabilities of the selected reference genes in the current study, the relative expression level of two transcription factors, HcWRKY28 and HcWRKY32, were investigated in two kenaf samples under conditions of drought and excess salinity, using one or two of the most stable reference genes, as well as the least stable gene for normalization, which 
242 had been determined by geNorm, NormFinder, and BestKeeper as described above (Tables 2-4; 243 Fig. 2). In A. thaliana, AtWRKY28 (At4g18170) plays a crucial role in protecting plants against 244 pathogen infections and oxidative stress. In our previous study, we found that kenaf $W R K Y 28$, a 245 homolog of AtWRKY28, was differentially expressed under abiotic stress conditions according to 246 the gene differential expression profiling analysis based on RNA-seq. We also found that 247 WRKY32 was actively upregulated in kenaf in response to drought and salinity stresses 248 (unpublished data). Therefore, the two genes were selected to further validate the usefulness of

249

250

251

252

253

254

255

256

257

258

259

260

261

262

263

264

265

266

267

268

269

270

271

272

273

274

275

276

277

278

279

280

281

282

the selected reference genes by qRT-PCR. In the current study, we selected the two reference genes with lowest $\mathrm{M}$ values, $18 \mathrm{~S} r R N A$ and $T U B \alpha$ and their combination (18S $r R N A+T U B \alpha$ ), and the gene $(U B C)$ with highest $M$ value, as the normalization factors to determine the expression patterns. As shown in Figure 3, the expression abundance of WRKY28 increased significantly after $6 \mathrm{~h}$ of salinity treatment, peaked at $8 \mathrm{~h}$, and thereafter decreased $(\mathrm{P}<0.01)$ (Fig. 3A), while WRKY32 peaked at $12 \mathrm{~h}(\mathrm{P}<0.01)$ (Fig. 3C) in the NaCl-treated samples. For PEG-treated samples, qRT-PCR analysis showed that the expression level of WRKY28 decreased from $0 \mathrm{~h}$ to $6 \mathrm{~h}$, increased at $8 \mathrm{~h}$, peaked at $12 \mathrm{~h}$, and then decreased $(\mathrm{P}<0.01)$ (Fig. 3B). In contrast, the expression level of WRKY32 increased at $12 \mathrm{~h}$, and peaked at $24 \mathrm{~h}$ with approximately 7.5-fold accumulation $(\mathrm{P}<0.01)$ (Fig. 3D). Salinity and drought stresses significantly increased the expression of WRKY28 by 4.5 - and 3.5-fold at $8 \mathrm{~h}$ and $12 \mathrm{~h}, W R K Y 32$ by 6.5 - and 7.5 -fold at $12 \mathrm{~h}$ and $24 \mathrm{~h}$, compared with that at $0 \mathrm{~h}$, respectively $(\mathrm{P}<0.01)$. These results are in accordance with the patterns of WRKY28 and WRKY32 in previously analysis. Moreover, the expression patterns of WRKY28 and WRKY32 showed similar trends across different experimental sets to those of $18 \mathrm{~S} r R N A$ and $T U B \alpha$ as reference genes either singly or in combination (Fig. 3), although some slight differences exist. However, when the expression of WRKY28 and WRKY32 was normalized using the reference gene with the highest $\mathrm{M}$ value (UBC) as an internal control, the expression pattern of WRKY28 and WRKY32 showed a significantly different changes, and the expression level was 5-fold lower than that of the genes with the lowest $\mathrm{M}$ values $(\mathrm{P}<0.01)$ (Fig. 3). These results indicate that $18 \mathrm{~S} r R N A$ and $T U B \alpha$ are suitable reference genes for gene expression normalization under conditions of drought and excess salinity in kenaf.

\section{Discussion}

Water deficiency and high salinity are responsible for the large margin existing between potential and real harvest yields in several crops worldwide (Mittler 2006; Wang et al. 2003). To adapt to adverse conditions, plants have evolved complicated mechanisms at multiple levels to increase stress tolerance. At the molecular level, some stress-response and -tolerant genes contribute to the plants' ability to cope with unfavorable environmental conditions (Rasmussen et al. 2013; Zhu 2002). Many studies on plant defense and stress mechanisms are increasingly based on gene expression analyses (Chuaqui et al. 2002). Real-time qRT-PCR has been widely used as an accurate and reliable method for the detection of gene expression and plays a considerable role in the study of molecular mechanisms of plant stress responses. To avoid bias caused by RNA integrity, cDNA synthesis, and tissue or cell activities, qRT-PCR uses internal reference genes, which should not fluctuate under different experimental treatments. However, 
many studies have found that the expression of reference genes vary considerably across different experimental conditions, and thus, it is proposed that the stability of candidate reference genes should be systematically evaluated prior to their use in qRT-PCR normalization (Czechowski et al. 2005; Guenin et al. 2009; Schmidt \& Delaney 2010). Kenaf is well known as a cellulosic source with both economic and ecological advantages. Recently, it has been used as an alternative raw material to wood in the pulp and paper industry to limit forest destruction and as nonwoven mats in the automotive and textile industries (Nishino et al. 2003; Villar et al. 2009). Therefore, breeding kenaf cultivars with tolerance to drought and salinity is of fundamental importance, and understanding plant response mechanisms to drought and salinity would greatly contribute to increases crop yield and efficient land usage (Mittler 2006; Suzuki et al. 2014; Wang et al. 2003). However, the limited available of suitable reference genes, which should be selected under systematic and specific experimental conditions, has allowed few applications of qRT-PCR for kenaf functional gene characterization.

In this study, we used the three different programs (geNorm, NormFinder and BestKeeper) to systematically evaluate the expression stability of candidate reference genes in kenaf under conditions of drought and excess salinity. Differences were observed among these three algorithms after comparisons of the ranking of the candidate reference genes (Tables 2-4; Fig. 2). This is an expected event due to the different statistical algorithms used to calculate stability associated with each method (Liu et al. 2012; Nicot et al. 2005). In addition, variations in single or combined stresses are indicative of the expression levels of reference genes and their responses to different stresses. Recent studies have revealed that the molecular and metabolic responses of plants to simultaneous stresses are unique and cannot be directly extrapolated from the responses of each of the stresses applied individually (Mittler 2006; Wang et al. 2003). After the analysis of data from salinity-treated samples, $T U B \alpha, 18 \mathrm{~S} r R N A$, and $R A N$ were ranked as the most stable reference genes by geNorm and BestKeeper (Table 2; Fig. 2A). For drought-treated samples, the top two reference genes (TUB $\alpha$ and $18 \mathrm{~S} r R N A$ ) identified by geNorm were the same as those determined by NormFinder, but not those assigned by BestKeeper (Table 3; Fig. 2B). In term of NaCl- and PEG-treated samples, $T U B \alpha$ and $18 \mathrm{~S} r R N A$ were ranked as the top two reference genes by geNorm (Table 4; Fig. 2C), ACT4 and $18 \mathrm{~S} r R N A$ by NormFinder, and $M Z A$ and $T U B \alpha$ by BestKeeper (Table 4).

Taken together, the results obtained from the three algorithms identified $T U B \alpha$ and $18 \mathrm{~S} r R N A$ as the best normalization factors in kenaf under conditions of drought and excess salinity. In this study, $T U B \alpha$ was identified as one of the top two reference genes, which was consistent with results in the developmental stages of G. $\max$ (Jian et al. 2008), biotic stress samples of C. melo (Kong et al. 2014), and PEG-treated samples of P. orientalis (Chang et al. 2012); however, this gene performed poorly in studies of L. usitatissimum (Huis et al. 2010) and Phyllostachys edulis (Fan et al. 2013), suggesting that the expression levels of reference genes are variable among different species. 18S $r R N A$, one of the most stable reference genes in the present study, was also the best reference gene during late blight exposure of $S$. tuberosum (Nicot et al. 2005), across leaf and root tissues of Cichorium intybus (Maroufi et al. 2010), and in barley yellow dwarf virus-infected cereals (Jarosova \& Kundu 2010), but it was the worst performer in $P$. orientalis 
(Chang et al. 2012), P. edulis (Fan et al. 2013), and viral infection of $N$. benthamiana (Liu et al. 2012). ACT4 was ranked as the third most stable reference gene analyzed by geNorm and NormFinder in samples subjected to drought stress (Table 3); this gene was also optimal for the different floral organs of $G$. hirsutum (Artico et al. 2010) and in diploid and tetraploid Chrysanthemum nankingense (Wang et al. 2015). In addition, MZA showed remarkably consistent expression during fruit development of G. hirsutum (Artico et al. 2010) and P. edulis (Fan et al. 2013) (namely $C A C$ ), and in the development of Solanum lycopersicon (ExpositoRodriguez et al. 2008) (namely $C A C$ ); these results were consistent with those calculated by BestKeeper in samples subjected to drought, as well as in the NaCl- and PEG-treated samples in our present study (Tables 3 and 4). The data also demonstrate that the expression levels of reference genes $P P 2 A, R A N, U B Q$, and $P T B$ were considerable variable in this study (Tables 2-4; Fig. 2). $P P 2 A$ was reported to be the most stable reference gene in the viral infection of $N$. benthamiana (Liu et al. 2012), different organs of G. hirsutum (Artico et al. 2010), and in PEGand heat-treated samples of Caragana intermedia (Zhu et al. 2013), but was unsatisfactory as a reference gene in C. melo (Kong et al. 2014). RAN was also the optimal performer in samples of $C$. melo treated with growth regulators (Kong et al. 2014) but was variable under conditions of excess salinity and drought in this study. $U B Q$, one of the most commonly used reference genes in qRT-PCR assays, showed variable expression in our study but was previously reported to be expressed stably in different organs of G. hirsutum (Artico et al. 2010) and in NaCl- and ABAtreated samples of $P$. orientalis (Chang et al. 2012). A novel reference gene identified in $A$. thaliana, PTB (Remans et al. 2008), has been reported as one of the most stably expressed gene in fruit development of $G$. hirsutum (Artico et al. 2010), but it was not suitable as a normalization factor in kenaf under conditions of excess salinity and drought according to the three algorithms. Previously, EFl $\alpha$ was the most highly recommended reference gene during biotic and abiotic stresses in both S. tuberosum (Nicot et al. 2005) and G. max (Saraiva et al. 2014). In this study, however, EFl $\alpha$ was ranked at the bottom by the three programs used. Similarly, the commonly used reference gene $U B C$ was the least stable gene in analyses from geNorm and NormFinder in all samples. Given these observations, we suggest that both EF1 $\alpha$ and $U B C$ should be carefully used as reference genes in kenaf under conditions of excess salinity and drought.

Finally, to validate the suitability of the reference genes revealed in this study, we analyzed the transcription profile of two WRKY genes, HcWRKY28 and HcWRKY32, in kenaf. HcWRKY28 is a homolog of AtWRKY28, which has been demonstrated as a key plant regulator against pathogen infections and oxidative stress in A. thaliana (Babitha et al. 2013; Chen et al. 2013). In this study, the expression of HcWRKY28 and HcWRKY32 was normalized using the most stable reference genes (TUB $\alpha, 18 \mathrm{~S} r R N A$, and a combination of both) and a less stable gene (UBC) as internal controls in kenaf under conditions of excess salinity and drought. The results showed that WRKY28 and WRKY32 expression were actively induced by $\mathrm{NaCl}$ and PEG treatments (Fig. 3) and were significantly increased after $6 \mathrm{~h}$ of $\mathrm{NaCl}$ treatment, peaking at $8 \mathrm{~h}$ and $12 \mathrm{~h}$ (Fig. 3A; 3C) $(\mathrm{P}<0.01)$, respectively; for drought samples, the expression level of WRKY28 decreased from $0 \mathrm{~h}$ to $6 \mathrm{~h}$, increased at $8 \mathrm{~h}$, and peaked at $12 \mathrm{~h}, W R K Y 32$ increased at $12 \mathrm{~h}$, and peaked at 
$24 \mathrm{~h}$ (Fig. 3B; 3D) $(\mathrm{P}<0.01)$. Salinity and drought stress significantly increased the expression of WRKY28 by 4.5 - and 3.5 -fold at $8 \mathrm{~h}$ and $12 \mathrm{~h}$, respectively $(\mathrm{P}<0.01)$, compared to the control group, while $W R K Y 32$ by 6.5 - and 7.5 -fold at $12 \mathrm{~h}$ and $24 \mathrm{~h}$, respectively $(\mathrm{P}<0.01)$. Moreover, the expression patterns of WRKY28 and WRKY32 showed similar trends under conditions of excess salinity and/or drought to those of $T U B \alpha$ and $18 \mathrm{~S} r R N A$ as reference genes, either singly or in combination (Fig. 3), with some slight differences. However, the data showed that the use of the most variable reference gene $U B C$ resulted in significantly expression changes in $W R K Y 28$ and WRKY32 compared to the normalized expression data obtained using $T U B \alpha, 18 \mathrm{~S} r R N A$, or a combination of both. These results indicate that the inappropriate utilization of reference genes without validation may generate bias in the analysis and lead to misinterpretation of qRT-PCR data.

\section{Conclusion}

To screen appropriate reference genes to normalize expression of target genes in kenaf under conditions of excess salinity and drought, 10 candidate reference genes were validated across 14 $\mathrm{NaCl}$ - and PEG-treated kenaf samples using three commonly used statistical algorithms: geNorm, NormFinder, and BestKeeper. The results revealed that $T U B \alpha$ and $18 \mathrm{~S} r R N A$ were identified as suitable reference genes for gene expression normalization in kenaf under conditions of excess salinity and/or drought. Furthermore, the expression analyses of WRKY28 and WRKY32 further validated that the combination of $T U B \alpha$ and $18 \mathrm{~S} r R N A$ as normalization factors was optimal in the present study. This study can benefit future research on the expression of genes in response to excess salinity and drought in kenaf.

Competing financial interests: The authors have declared that no competing financial interests exist.

\section{References}

Andersen CL, Jensen JL, and Orntoft TF. 2004. Normalization of real-time quantitative reverse transcription-PCR data: A model-based variance estimation approach to identify genes suited for normalization, applied to bladder and colon cancer data sets. Cancer Research 64:5245-5250.

Artico S, Nardeli SM, Neto OBO, Grossi-de-Sa MF, and Alves-Ferreira M. 2010. Identification and evaluation of new reference genes in Gossypium hirsutum for accurate normalization of real-time quantitative RT-PCR data. BMC Plant Biology 10.

Ayadi R, Hamrouni L, Hanana M, Bouzid S, Trifi M, and Khouja ML. 2011. In vitro propagation and regeneration of an industrial plant kenaf (Hibiscus cannabinus L.). Industrial Crops and Products 33:474-480.

Babitha KC, Ramu SV, Pruthvi V, Mahesh P, Nataraja KN, and Udayakumar M. 2013. Co-expression of AtbHLH17 and AtWRKY28 confers resistance to abiotic stress in Arabidopsis. Transgenic Research 22:327-341.

Banuelos GS, Bryla DR, and Cook CG. 2002. Vegetative production of kenaf and canola under 
irrigation in central California. Industrial Crops and Products 15:237-245.

Bartels D, and Sunkar R. 2005. Drought and Salt Tolerance in Plants. Critical Reviews in Plant Sciences 24:23-58.

Bézier A, Lambert B, and Baillieul F. 2002. Study of defense-related gene expression in grapevine leaves andberries infected with Botrytis cinerea. European J ournal of Plant Pathology 108:111-120.

Bhardwaj HL, Webber CL, and Sakamoto GS. 2005. Cultivation of kenaf and sunn hemp in the mid-Atlantic United States. Industrial Crops and Products 22:151-155.

Bustin SA. 2002. Quantification of mRNA using real-time reverse transcription PCR (RT-PCR): trends and problems. Journal of Molecular Endocrinology 29.

Chang EM, Shi SQ, Liu JF, Cheng TL, Xue L, Yang XY, Yang WJ, Lan Q, and Jiang ZP. 2012. Selection of Reference Genes for Quantitative Gene Expression Studies in Platycladus orientalis (Cupressaceae) Using Real-Time PCR. PLoS One 7.

Chen XT, Liu J, Lin GF, Wang AR, Wang ZH, and Lu GD. 2013. Overexpression of AtWRKY28 and AtWRKY75 in Arabidopsis enhances resistance to oxalic acid and Sclerotinia sclerotiorum. Plant Cell Reports 32:1589-1599.

Chuaqui RF, Bonner RF, Best CJM, Gillespie JW, Flaig MJ, Hewitt SM, Phillips JL, Krizman DB, Tangrea MA, Ahram M, Linehan WM, Knezevic V, and Emmert-Buck MR. 2002. Post-analysis follow-up and validation of microarray experiments. Nature Genetics 32:509-514.

Curtis PS, and Läuchli A. 1985. Responses of Kenaf to Salt Stress: Germination and Vegetative Growth. Crop Science 25:944-949.

Czechowski T, Stitt M, Altmann T, Udvardi MK, and Scheible WR. 2005. Genome-wide identification and testing of superior reference genes for transcript normalization in Arabidopsis. Plant Physiology 139:5-17.

Dean JD, Goodwin PH, and Hsiang T. 2002. Comparison of Relative RT-PCR and Northern blot analyses to measure expression of $\beta$-1,3-glucanase in Nicotiana benthamiana infected with Colltotrichum destructivum. Plant Molecular Biology Reporter 20:347-356.

Exposito-Rodriguez M, Borges AA, Borges-Perez A, and Perez JA. 2008. Selection of internal control genes for quantitative real-time RT-PCR studies during tomato development process. BMC Plant Biology 8.

Fan CJ, Ma JM, Guo QR, Li XT, Wang H, and Lu MZ. 2013. Selection of Reference Genes for Quantitative Real-Time PCR in Bamboo (Phyllostachys edulis). PLoS One 8.

Francois LE, Donovan TJ, and Maas EV. 1992. Yield, Vegetative Growth, and Fiber Length of Kenaf Grown on Saline Soil. Agronomy Journal 84:592-598.

Guenin S, Mauriat M, Pelloux J, Van Wuytswinkel O, Bellini C, and Gutierrez L. 2009. Normalization of qRT-PCR data: the necessity of adopting a systematic, experimental conditions-specific, validation of references. Journal of Experimental Botany 60:487-493.

Huis R, Hawkins S, and Neutelings G. 2010. Selection of reference genes for quantitative gene expression normalization in flax (Linum usitatissimum L.). BMC Plant Biology 10.

Jarosova J, and Kundu JK. 2010. Validation of reference genes as internal control for studying 
viral infections in cereals by quantitative real-time RT-PCR. BMC Plant Biology 10.

Jian B, Liu B, Bi YR, Hou WS, Wu CX, and Han TF. 2008. Validation of internal control for gene expression study in soybean by quantitative real-time PCR. BMC Molecular Biology 9.

Kong QS, Yuan JX, Niu PH, Xie JJ, Jiang W, Huang Y, and Bie ZL. 2014. Screening Suitable Reference Genes for Normalization in Reverse Transcription Quantitative Real-Time PCR Analysis in Melon. PLoS One 9.

Liu DS, Shi LD, Han CG, Yu JL, Li DW, and Zhang YL. 2012. Validation of Reference Genes for Gene Expression Studies in Virus-Infected Nicotiana benthamiana Using Quantitative Real-Time PCR. PLoS One 7.

Long XY, Wang JR, Ouellet T, Rocheleau H, Wei YM, Pu ZE, Jiang QT, Lan XJ, and Zheng YL. 2010. Genome-wide identification and evaluation of novel internal control genes for Q-PCR based transcript normalization in wheat. Plant Molecular Biology 74:307-311.

Maroufi A, Van Bockstaele E, and De Loose M. 2010. Validation of reference genes for gene expression analysis in chicory (Cichorium intybus) using quantitative real-time PCR. BMC Molecular Biology 11.

Mittler R. 2006. Abiotic stress, the field environment and stress combination. Trends in Plant Science 11:15-19.

Narsai R, Ivanova A, Ng S, and Whelan J. 2010. Defining reference genes in Oryza sativa using organ, development, biotic and abiotic transcriptome datasets. BMC Plant Biology 10.

Nicot N, Hausman JF, Hoffmann L, and Evers D. 2005. Housekeeping gene selection for realtime RT-PCR normalization in potato during biotic and abiotic stress. Journal of Experimental Botany 56:2907-2914.

Nishino T, Hirao K, Kotera M, Nakamae K, and Inagaki H. 2003. Kenaf reinforced biodegradable composite. Composites Science and Technology 63:1281-1286.

Pfaffl MW, Tichopad A, Prgomet C, Neuvians TP. 2004. Determination of stable housekeeping genes, differentially regulated target genes and sample integrity: BestKeeperExcel-based tool using pair-wise correlations. Biotechnology Letters 26:509-515.

Rasmussen S, Barah P, Suarez-Rodriguez MC, Bressendorff S, Friis P, Costantino P, Bones AM, Nielsen HB, and Mundy J. 2013. Transcriptome responses to combinations of stresses in Arabidopsis. Plant Physiology 161:1783-1794.

Remans T, Smeets K, Opdenakker K, Mathijsen D, Vangronsveld J, and Cuypers A. 2008. Normalisation of real-time RT-PCR gene expression measurements in Arabidopsis thaliana exposed to increased metal concentrations. Planta 227:1343-1349.

Samanthi PW, Puad AM, Suhaimi N, Kumar SM, and NorAini AS. 2013. In Vitro Shoot Regeneration from Leaf Explants of Kenaf (Hibiscus cannabinus L.). Saina Malaysiana 42:1505-1510.

Saraiva KD, Fernandes de Melo D, Morais VD, Vasconcelos IM, and Costa JH. 2014. Selection of suitable soybean EF1alpha genes as internal controls for real-time PCR analyses of tissues during plant development and under stress conditions. Plant Cell Reports 33:14531465.

Schmidt GW, and Delaney SK. 2010. Stable internal reference genes for normalization of real- 
time RT-PCR in tobacco (Nicotiana tabacum) during development and abiotic stress. Molecular Genetics and Genomics 283:233-241.

Suzuki N, Rivero RM, Shulaev V, Blumwald E, and Mittler R. 2014. Abiotic and biotic stress combinations. New Phytologist 203:32-43.

Vandesompele J, De Preter K, Pattyn F, Poppe B, Van Roy N, De Paepe A, and Speleman F. 2002. Accurate normalization of real-time quantitative RT-PCR data by geometric averaging of multiple internal control genes. Genome Biology 3.

Villar JC, Revilla E, Gómez N, Carbajo JM, and Simón JL. 2009. Improving the use of kenaf for kraft pulping by using mixtures of bast and core fibers. Industrial Crops and Products 29:301-307.

Wang HB, Chen SM, Jiang JF, Zhang F, and Chen FD. 2015. Reference gene selection for cross-species and cross-ploidy level comparisons in Chrysanthemum spp. Scientific Reports $\mathbf{5}$.

Wang WX, Vinocur B, and Altman A. 2003. Plant responses to drought, salinity and extreme temperatures: towards genetic engineering for stress tolerance. Planta 218:1-14.

Zhu JF, Zhang LF, Li WF, Han SY, Yang WH, and Qi LW. 2013. Reference Gene Selection for Quantitative Real-time PCR Normalization in Caragana intermedia under Different Abiotic Stress Conditions. PLoS One $\mathbf{8 .}$

Zhu JK. 2002. Salt and drought stress signal transduction in plants. Annu Rev Plant Biol 53:247-273.

\section{Figure Legends}

Fig. 1. Expression levels of $\mathbf{1 0}$ candidate reference genes across all experimental samples. Each box indicates $25 / 75$ percentiles. Whisker caps represent $10 / 90$ percentiles. The median is depicted by the line across the box, and all outliers are indicated by dots.

Fig. 2. geNorm ranking of candidate reference genes and pairwise variation (V) to determine the optimal number of reference genes. (A) Expression stability of 10 candidate reference genes after $\mathrm{NaCl}$ treatment. (B) Expression stability of 10 candidate reference genes after PEG treatment. (C) Expression stability of 10 candidate reference genes after $\mathrm{NaCl}$ and PEG treatments. (D) The pairwise variation $\left(\mathrm{V}_{\mathrm{n}} / \mathrm{V}_{\mathrm{n}+1}\right)$ was calculated between normalization factors $\mathrm{NF}_{\mathrm{n}}$ and $\mathrm{NF}_{\mathrm{n}+1}$ by geNorm to determine the optimal number of reference genes for accurate normalization.

Fig. 3. Relative increase in expression of WRKY28 and WRKY32 using the selected reference genes. Relative expression of $W R K Y 28$ (Fig. A; B) and WRKY32 (Fig. C; D) was normalized using the most stable reference genes: single $T U B \alpha$, single $18 \mathrm{~S} r R N A$, or $T U B \alpha+$ 18S $r R N A$ in sample sets across NaCl-treated samples (A and C) and PEG- treated samples (B and D). cDNA samples were taken from the same set used for gene expression stability analysis. 
1

Expression levels of 10 candidate reference genes across all experimental samples.

Each box indicates $25 / 75$ percentiles. Whisker caps represent $10 / 90$ percentiles. The median is depicted by the line across the box, and all outliers are indicated by dots.

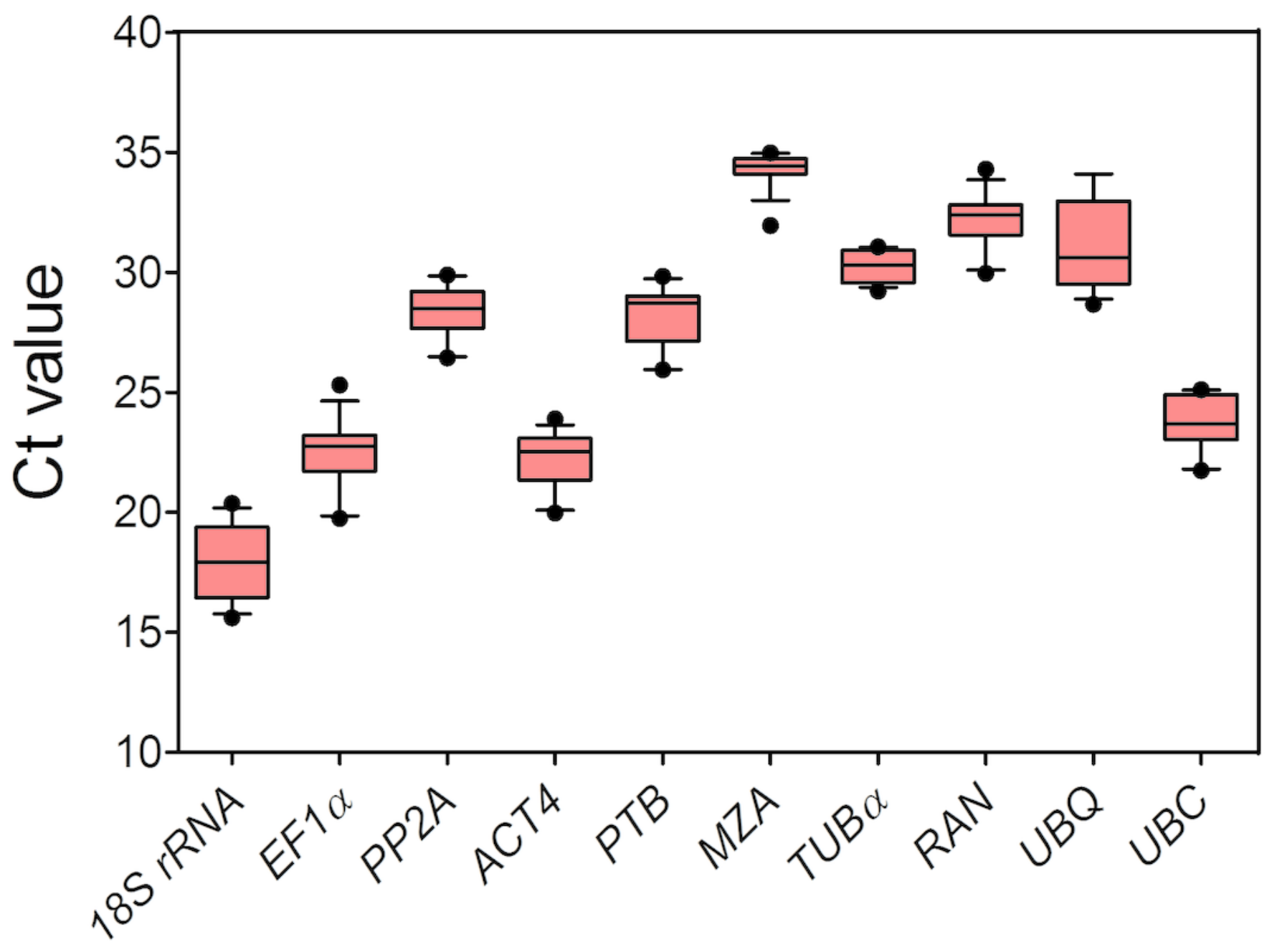


geNorm ranking of candidate reference genes and pairwise variation $(\mathrm{V})$ to determine the optimal number of reference genes.

(A) Expression stability of 10 candidate reference genes after $\mathrm{NaCl}$ treatment. (B) Expression stability of 10 candidate reference genes after PEG treatment. (C) Expression stability of 10 candidate reference genes after $\mathrm{NaCl}$ and PEG treatments. (D) The pairwise variation $(\mathrm{Vn} / \mathrm{Vn}+1)$ was calculated between normalization factors $\mathrm{NFn}$ and $\mathrm{NFn}+1$ by geNorm to determine the optimal number of reference genes for accurate normalization.
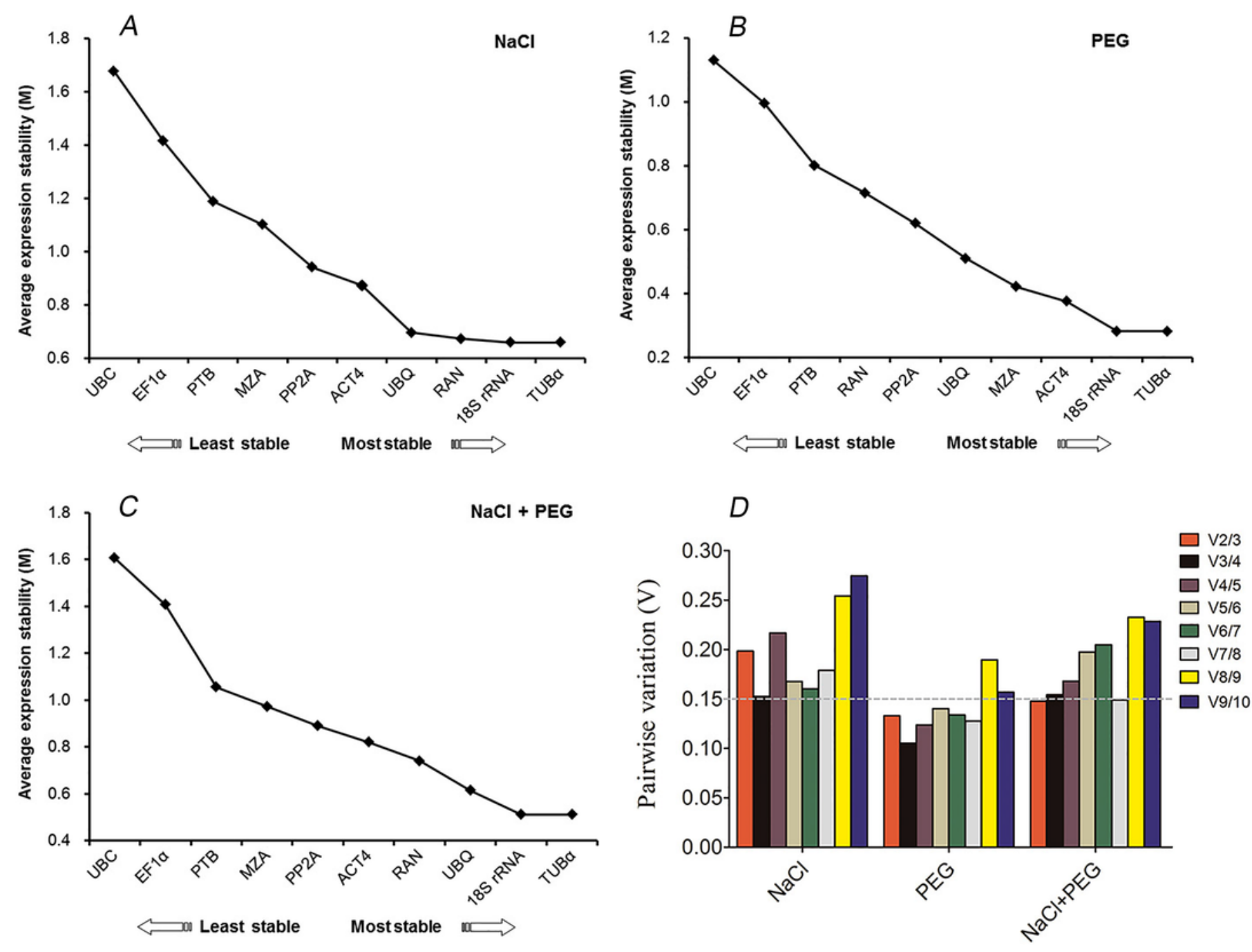


\section{3}

Relative increase in expression of WRKY28 and WRKY32 using the selected reference genes.

Relative expression of WRKY28 (Fig. A; B) and WRKY32 (Fig. C; D) was normalized using the most stable reference genes: single TUB $\alpha$, single $18 \mathrm{~S}$ rRNA, or TUB $\alpha+18 \mathrm{~S}$ rRNA in sample sets across NaCl-treated samples ( $\mathrm{A}$ and $\mathrm{C}$ ) and PEG- treated samples (B and D). CDNA samples were taken from the same set used for gene expression stability analysis.
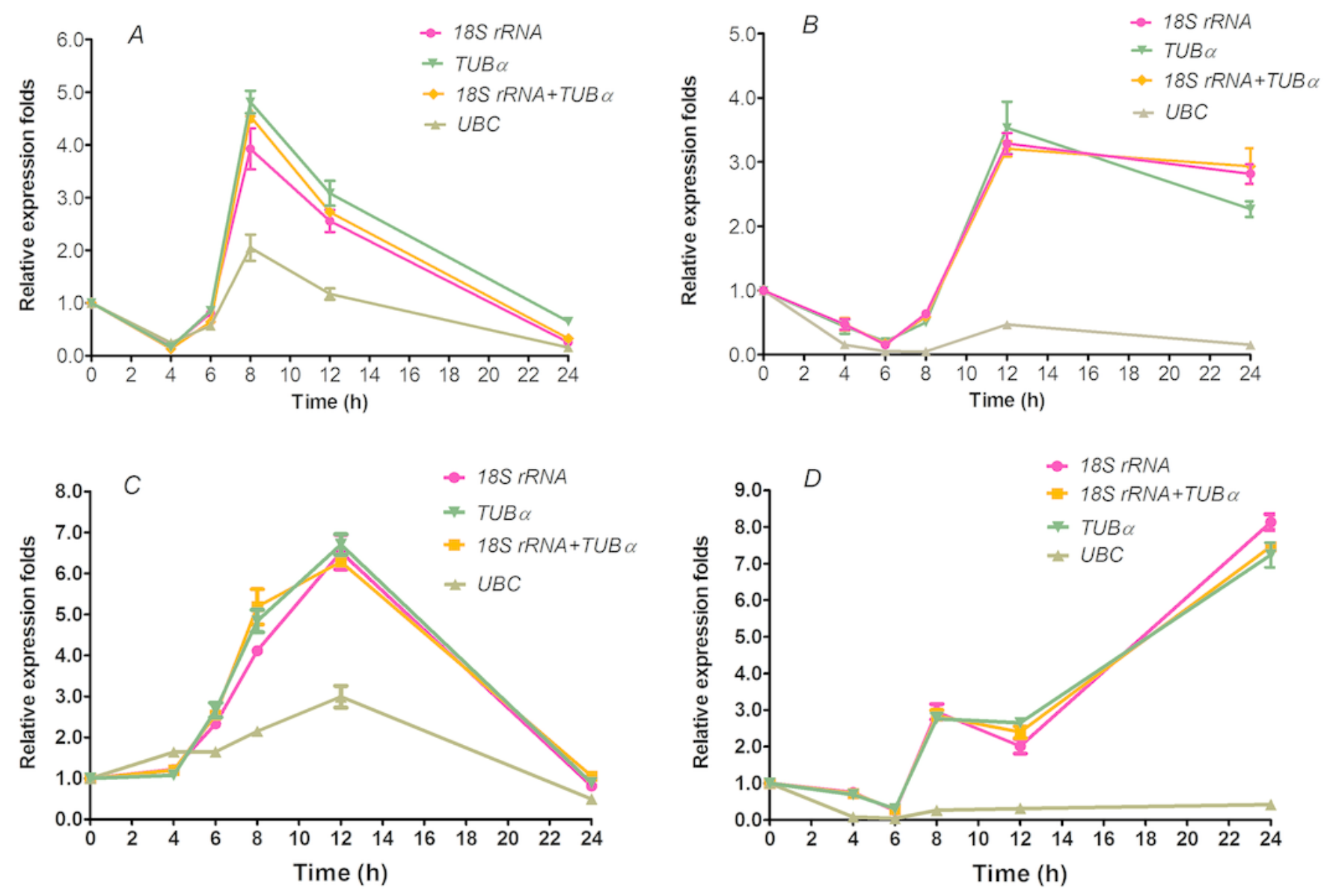


\section{Table $\mathbf{1}$ (on next page)}

Primer sequences and amplicon characteristics of the 10 candidate internal control genes evaluated in this study 
Table 1. Primer sequences and amplicon characteristics of the 10 candidate internal control genes evaluated in this study.

\begin{tabular}{|c|c|c|c|c|c|c|c|c|c|}
\hline Gene & $\begin{array}{l}\text { A. thaliana } \\
\text { ortholog locus }\end{array}$ & $\begin{array}{l}\text { Gene } \\
\text { description }\end{array}$ & $\begin{array}{l}\text { Primer sequence } \\
\text { F / R (5'-3') }\end{array}$ & $\begin{array}{l}\text { Product } \\
\operatorname{size}(b p)\end{array}$ & $\begin{array}{l}\text { Efficiency } \\
(\%)\end{array}$ & $\mathbf{R}^{2}$ & $\begin{array}{l}\text { Mean } \\
\text { Ct }\end{array}$ & SD & \\
\hline $18 \mathrm{~S} r R N A$ & At3g41768 & $18 \mathrm{~S}$ ribosomal RNA & $\begin{array}{l}\text { CTACGTCCCTGCCCTTTGTA } \\
\text { GGTTCACCTACGGAAACCTTG }\end{array}$ & 175 & 104.1 & 0.9949 & 17.89 & 1.546 & \\
\hline$A C T 4$ & At5g09810 & Actin 4 & $\begin{array}{l}\text { TTGCAGACCGTATGAGCAAG } \\
\text { ATCCTCCGATCCAGACACTG }\end{array}$ & 166 & 105.4 & 0.9967 & 22.17 & 1.240 & \\
\hline$M Z A$ & At5g46630 & $\begin{array}{l}\text { Clathrin adaptor complexes } \\
\text { medium subunit family protein }\end{array}$ & $\begin{array}{l}\text { CCGTCAGACAGATTGGAGGT } \\
\text { AAAGCAACAGCCTCAACGAC }\end{array}$ & 154 & 106.3 & 0.9949 & 34.28 & 0.7416 & \\
\hline$E F 1 \alpha$ & At5g60390 & Elongation factor 1-alpha & $\begin{array}{l}\text { TCCCCATCTCTGGTTTTGAG } \\
\text { CTTGGGCTCATTGATCTGGT }\end{array}$ & 130 & 113.8 & 0.9960 & 22.46 & 1.542 & \\
\hline$R A N$ & At5g59840 & $\begin{array}{l}\text { Ras-related small } \\
\text { GTP-binding protein }\end{array}$ & $\begin{array}{l}\text { GCCATGCCGATAAGAACATT } \\
\text { GTGAAGGCAGTCTCCCACAT }\end{array}$ & 167 & 97.13 & 0.9997 & 32.18 & 1.151 & \\
\hline$T U B \alpha$ & At4g14960 & Alpha-tubulin & $\begin{array}{l}\text { AATGCTTGCTGGGAGCTTTA } \\
\text { GTGGAATAACTGGCGGTACG }\end{array}$ & 213 & 105.1 & 0.9992 & 30.24 & 0.6500 & \\
\hline$P P 2 A$ & Atlg59830 & $\begin{array}{l}\text { Catalytic subunit of protein } \\
\text { phosphatase } 2 \mathrm{~A}\end{array}$ & $\begin{array}{l}\text { GATCCTTGTGGAGGAGTGGA } \\
\text { GCGAAACAGTTCGACGAGAT }\end{array}$ & 201 & 108.9 & 0.9985 & 28.38 & 1.149 & \\
\hline$U B C$ & At3g52560 & $\begin{array}{l}\text { Ubiquitin-conjugating } \\
\text { enzyme like protein }\end{array}$ & $\begin{array}{l}\text { CTGCCATCTCCTTTTTCAGC } \\
\text { CGAGTGTCCGTTTTCATTCA }\end{array}$ & 150 & 118.6 & 0.9981 & 23.72 & 1.169 & \\
\hline$P T B$ & At3g01150 & $\begin{array}{l}\text { Polypyrimidine tract-binding } \\
\text { protein homolog }\end{array}$ & $\begin{array}{l}\text { GGTTACCATTGAGGGTGTGG } \\
\text { GTGCACAAAACCAAATGCAG }\end{array}$ & 158 & 109.4 & 0.9993 & 28.14 & 1.321 & \\
\hline$U B Q$ & At5g20620 & Ubiquitin & $\begin{array}{l}\text { TCTTTGCAGGGAAGCAACTT } \\
\text { CTGCATAGCAGCAAGCTCAC }\end{array}$ & 219 & 102.5 & 0.9993 & 31.15 & 1.944 & \\
\hline
\end{tabular}


Table 2 (on next page)

Expression stability of $\mathrm{H}$. cannabinus candidate reference genes under salinity stress 
1 Table 2. Expression stability of H. cannabinus candidate reference genes under salinity stress

\begin{tabular}{ccccccccr}
\hline \multirow{2}{*}{ Rank } & \multicolumn{2}{c}{ geNorm } & \multicolumn{2}{c}{ NormFinder } & \multicolumn{4}{c}{ BestKeeper } \\
\cline { 2 - 8 } & Gene & Stability & Gene & Stability & Gene & CV \pm SD & r & p-value \\
\hline 1 & $T U B \alpha$ & 0.65 & $P P 2 A$ & 0.11 & $T U B \alpha$ & $1.50 \pm 0.46$ & -0.186 & 0.692 \\
2 & $18 \mathrm{~S} r R N A$ & 0.65 & $A C T 4$ & 0.11 & $18 \mathrm{~S} r R N A$ & $1.96 \pm 0.67$ & 0.911 & 0.004 \\
3 & $R A N$ & 0.67 & $18 \mathrm{~S} r R N A$ & 0.40 & $R A N$ & $1.97 \pm 0.63$ & 0.307 & 0.504 \\
4 & $U B Q$ & 0.70 & $P T B$ & 0.51 & $P P 2 A$ & $3.38 \pm 0.94$ & 0.949 & 0.001 \\
5 & $A C T 4$ & 0.87 & $U B Q$ & 0.56 & $M Z A$ & $3.99 \pm 0.67$ & 0.014 & 0.977 \\
6 & $P P 2 A$ & 0.94 & $R A N$ & 0.83 & $U B Q$ & $3.99 \pm 1.28$ & 0.691 & 0.085 \\
7 & $M Z A$ & 1.10 & $T U B \alpha$ & 0.93 & $P T B$ & $4.53 \pm 1.25$ & 0.958 & 0.001 \\
8 & $P T B$ & 1.19 & $M Z A$ & 1.14 & $U B C$ & $5.15 \pm 1.20$ & 0.952 & 0.001 \\
9 & $E F 1 \alpha$ & 1.41 & $E F 1 \alpha$ & 1.35 & $E F 1 \alpha$ & $6.30 \pm 1.36$ & 0.943 & 0.001 \\
10 & $U B C$ & 1.68 & $U B C$ & 1.91 & $A C T 4$ & $6.33 \pm 1.38$ & 0.959 & 0.001 \\
\hline
\end{tabular}

2 


\section{Table 3(on next page)}

Expression stability of $\mathrm{H}$. cannabinus candidate reference genes under drought stress 
1 Table 3. Expression stability of H. cannabinus candidate reference genes under drought stress

\begin{tabular}{ccccccccr}
\hline \multirow{2}{*}{ Rank } & \multicolumn{2}{c}{ geNorm } & \multicolumn{2}{c}{ NormFinder } & \multicolumn{4}{c}{ BestKeeper } \\
\cline { 2 - 9 } & Gene & Stability & Gene & Stability & Gene & CV \pm SD & r & p-value \\
\hline 1 & $18 \mathrm{~S} r R N A$ & 0.28 & $18 \mathrm{~S} r R N A$ & 0.12 & $M Z A$ & $0.72 \pm 0.25$ & 0.246 & 0.593 \\
2 & $T U B \alpha$ & 0.28 & $T U B \alpha$ & 0.13 & $T U B \alpha$ & $1.54 \pm 0.46$ & 0.837 & 0.019 \\
3 & $A C T 4$ & 0.38 & $A C T 4$ & 0.18 & $P P 2 A$ & $2.21 \pm 0.64$ & 0.424 & 0.342 \\
4 & $M Z A$ & 0.42 & $U B Q$ & 0.31 & $A C T 4$ & $2.32 \pm 0.52$ & 0.819 & 0.024 \\
5 & $U B Q$ & 0.51 & $M Z A$ & 0.34 & $P T B$ & $2.40 \pm 0.69$ & 0.601 & 0.154 \\
6 & $P P 2 A$ & 0.62 & $P P 2 A$ & 0.65 & $U B C$ & $2.65 \pm 0.64$ & 0.766 & 0.044 \\
7 & $R A N$ & 0.71 & $P T B$ & 0.68 & $E F 1 \alpha$ & $3.15 \pm 0.74$ & 0.789 & 0.035 \\
8 & $P T B$ & 0.80 & $R A N$ & 0.76 & $R A N$ & $3.50 \pm 1.13$ & 0.871 & 0.011 \\
9 & $E F 1 \alpha$ & 0.99 & $E F 1 \alpha$ & 1.08 & $U B Q$ & $3.72 \pm 1.12$ & 0.640 & 0.122 \\
10 & $U B C$ & 1.13 & $U B C$ & 1.09 & $18 \mathrm{~S} r R N A$ & $4.47 \pm 0.85$ & 0.940 & 0.002 \\
\hline
\end{tabular}

2 


\section{Table 4(on next page)}

Expression stability of $\mathrm{H}$. cannabinus candidate reference genes under salinity and drought stress 
1 Table 4. Expression stability of H. cannabinus candidate reference genes under salinity and 2 drought stress

\begin{tabular}{ccccccccr}
\hline \multirow{2}{*}{ Rank } & \multicolumn{2}{c}{ geNorm } & \multicolumn{2}{c}{ NormFinder } & \multicolumn{3}{c}{ BestKeeper } \\
\cline { 2 - 9 } & Gene & Stability & Gene & Stability & Gene & CV \pm SD & r & p-value \\
\hline 1 & $T U B a$ & 0.51 & $A C T 4$ & 0.20 & $M Z A$ & $1.31 \pm 0.45$ & 0.117 & 0.689 \\
2 & $18 \mathrm{~S} r R N A$ & 0.51 & $18 \mathrm{~S} r R N A$ & 0.34 & $T U B a$ & $1.89 \pm 0.57$ & -0.100 & 0.732 \\
3 & $U B Q$ & 0.61 & $U B Q$ & 0.41 & $R A N$ & $2.66 \pm 0.86$ & 0.561 & 0.037 \\
4 & $R A N$ & 0.74 & $P P 2 A$ & 0.42 & $P P 2 A$ & $3.24 \pm 0.92$ & 0.832 & 0.001 \\
5 & $A C T 4$ & 0.82 & $P T B$ & 0.58 & $U B C$ & $3.88 \pm 0.92$ & 0.903 & 0.001 \\
6 & $P P 2 A$ & 0.89 & $T U B a$ & 0.64 & $P T B$ & $3.89 \pm 1.09$ & 0.883 & 0.001 \\
7 & $M Z A$ & 0.97 & $R A N$ & 0.76 & $A C T 4$ & $4.42 \pm 0.98$ & 0.910 & 0.001 \\
8 & $P T B$ & 1.06 & $M Z A$ & 0.90 & $E F 1 a$ & $4.89 \pm 1.10$ & 0.915 & 0.001 \\
9 & $E F 1 a$ & 1.41 & $E F 1 \alpha$ & 1.30 & $U B Q$ & $5.44 \pm 1.70$ & 0.243 & 0.401 \\
10 & $U B C$ & 1.61 & $U B C$ & 1.62 & $18 \mathrm{~S} r R N A$ & $6.84 \pm 1.22$ & 0.903 & 0.001 \\
\hline
\end{tabular}

3 